Plant Tissue Cult. \& Biotech. 18(1): 25-35, 2008 (June)

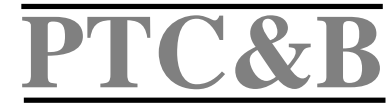

\title{
Effects of Growth Regulators on In vitro Propagation and Tuberization of Four Dioscorea Species
}

\section{Md. Tariqul Islam¹, E. R. Joachim Keller and D. Philibert Dembele $^{2}$}

Institute of Plant Genetics and Crop Plant Research (IPK), Corrensstrasse 3, D-06466 Gatersleben, Germany

Key words: Dioscorea spp., Microtuber, Nodal culture, Propagation

\begin{abstract}
Nodal explants of 12 accessions from four species of yam (Dioscorea spp.) were cultured for six weeks on MS to evaluate the influence of IAA, Kn, NAA and BAP on the production of leaves and microtubers. Four Dioscorea polystachya Turcz., three each of D. bulbifera L. and D. sansibarensis Pax. and two D. japonica Thunb. accessions were used. Five and $10 \mathrm{mg} / \mathrm{l}$ of $\mathrm{Kn}$ along with IAA and sucrose, and 0.2 and $0.5 \mathrm{mg} / 1$ of NAA, sucrose and with or without BAP were used in four treatments. The accessions Yam 23 and Yam 25 of D. sansibarensis failed to initiate any leaf under four treatments. The remaining accessions produced 0.11 to 1.76 leaves per explant. The medium containing IAA with higher concentration of $\mathrm{Kn}(10 \mathrm{mg} / \mathrm{l})$ and 3\% sucrose was found to be best for in vitro production of leaf $(0.71 /$ explant $)$ and the most productive species was $D$. japonica (1.36), followed by D. polystachya (1.19/explant). At the same culture period, Yam 16 of D. bulbifera failed to initiate any microtuber at IAA with $\mathrm{Kn}$, and NAA with or without BAP. The remaining accessions produced 0.09 to 1.15 microtubers per explant. Lower concentration of $\mathrm{Kn}(5 \mathrm{mg} / \mathrm{l})$ with IAA and sucrose was favourable for producing microtubers (0.61/explant on an average), the best species being D. sansibarensis (1.27) followed by D. japonica (0.59/ explant). Finally, the presence of BAP adversely affected the production of microtuber among Dioscorea species.
\end{abstract}

\section{Introduction}

The genus Dioscorea comprises about 700 species of which 11 are used as a source of food. They contain a good deal of starch, vitamin $C$ and other nutrients. Yams are the staple foodstuff for millions in many tropical and subtropical countries and are a secondary food for many millions more (Onwueme 1978). They are also used for people at times of famine. Yams are cultivated in large scale in West

1Present and corresponding address: Plant Genetic Resources Centre, Bangladesh Agricultural Research Institute (BARI), Joydebpur, Gazipur-1701, Bangladesh.

E.mail: tariqulislam_1999@yahoo.com 
Africa, Southeast Asia including adjacent parts of China, Japan and Oceania, and the Caribbean. It is grown all over Bangladesh. In addition, many species of yam contain small amount of sapogenins and alkaloids of medicinal value. Both wild and cultivated species are multiplied by conventional methods which are quite slow (Lauzer et al. 1992).

Nodal explants were used for rapid propagation of yam (Chaturvedi et al. 1982). In vitro production of microtubers has been attracted for plant propagation in yam because of its easy handling specially in international germplasm exchange. The micropropagation of elite cultivars and the induction of microtubers can provide an excellent means for both storage and rapid, inexpensive delivery of clonally propagated yam varieties to the field. A number of factors have been identified in tuber formation (Ammirato 1984, Forsyth and Van Staden 1984, Mantell and Hugo 1989, Ng 1988), but the information is far from being abundant. Contrasting results have been observed by different authors working with different species. Four species of different origins and characteristics have been selected in this study. Dioscorea polystachya (also known as Chinese yam) is native to eastern Asia, where it is cultivated for its edible tubers. In North America, it is planted as a garden ornamental and has become naturalized in major parts of the eastern United States. Dioscorea bulbifera (aerial yam and potato yam) is the most widely distributed of all Dioscorea species. It is found throughout the tropics and is thought to be the native to both Africa and Asia. The bulbils are eaten. Dioscorea sansibarensis (Zanzibar yam), an ornamental species the native to tropical Africa, is widely cultivated for its large, unusually shaped leaves. Axillary bulbils shed from mature plants were observed to be growing vigorously. Both the tubers and axillary bulbils of this species are toxic (Flora of North America 2006, Keller 2001). The temperate species D. japonica (Japanese yam) is distributed in East Asia, China, Korea and Japan (Coursey 1967). This species produces consumable aerial and underground tubers. In vitro production of microtubers has been reported in a number of Dioscorea species. Factors known to influence the tuberization process includes growth regulators (Ammirato 1982, Asahira and Nitsch 1968, Uduebo 1971), sucrose concentration (Asahira and Yazawa 1979), nitrogen supply (Asahira and Yazawa 1979, Mantell and Hugo 1989) and photoperiod (Jean and Cappadocia 1991). A good number of tropical, subtropical and temperate yam accessions are maintained at the Institute of Plant Genetics and Crop Plant Research (IPK), Germany. Systematic research such as propagation, in vitro storage and cryopreservation protocol development on yam (Leunufna and Keller 2003) has been done at IPK. In the first attempt, the influence of physical factors such as light, temperature, hot and cold water treatment, surface sterilization period etc. on in vitro seed germination of five different species of yam studied (Islam et al. 2004). Very little information 
is available of $D$. polystachya, D. bulbifera, D. sansibarensis and D. japonica on in vitro propagation and their tuberization. Therefore, we investigated the effects of some growth regulators on in vitro propagation and tuberization of the four species of yam.

\section{Materials and Methods}

The work was carried out at the Institute of Plant Genetics and Crop Plant Research (IPK) Gatersleben, Germany. The experiment was conducted with 12 accessions from four species of yam. The accessions were Yam 15, Yam 18, Yam 19 and Yam 26 from D. polystachya Turcz., Yam 16, Yam 21 and Yam 24 from D. bulbifera L., Yam 17, Yam 23 and Yam 25 from sansibarensis Pax., and Yam 20 and Yam 22 from D. japonica Thunb. Yam 16 was obtained as aerial tubers from Botanical garden of the Goethe University at Frankfurt Main, Germany. Yam 19 was obtained from the Botanical Garden of the University of Ferrara, and Yam 21 was obtained from the University of Padua both accessions from Italy. The remaining accessions were provided by the In vitro Storage and Cryopreservation Laboratory, IPK, Germany. Tubers of all accessions were grown in the glass house of about $25^{\circ} \mathrm{C}$ except Yam 18, which was grown outdoor in IPK. The vines of all the accessions grew long enough with aerial tubers. In this study, nodal explants were used from in vitro plantlets three months after their establishment from the terminal portion of the ex situ grown vines (Table 1).

Nodal explants of about $3 \mathrm{~cm}$ length were used after removal of the leaf and trimming of the petiole. They were surface disinfected with $70 \%$ ethanol and then with sodium hypochlorite (effective chlorine concentration $3 \%$ ) and Tween 20 ( 2 - 3 drops) for $15 \mathrm{~min}$, then rinsed three times in sterile distilled water. Basal media contained MS macro- and micro elements and $0.1 \mathrm{mg} / 1$ thiamine. In order to assess the potential of the cultures to produce leaves and microplants, the basal MS was supplemented with different concentrations of growth regulators and sucrose. The following treatments were used. T1 - $2 \mathrm{mg} / 1 \mathrm{IAA}+5 \mathrm{mg} / 1 \mathrm{Kn}$ $+3 \%$ sucrose, $\mathrm{T} 2-2 \mathrm{mg} / 1 \mathrm{IAA}+10 \mathrm{mg} / 1 \mathrm{Kn}+3 \%$ sucrose, $\mathrm{T} 3-0.2 \mathrm{mg} / 1 \mathrm{NAA}+$ $0.5 \mathrm{mg} / 1 \mathrm{BAP}+3 \%$ sucrose and T $4-0.5 \mathrm{mg} / 1 \mathrm{NAA}+2 \%$ sucrose.

The $\mathrm{pH}$ was adjusted to 5.8 . The medium was autoclaved at $121^{\circ} \mathrm{C}$ for 25 min. Nodal explants were excised aseptically and inoculated into long test tube $(25 \times 150 \mathrm{~mm})$ covered with aluminum foil with $10 \mathrm{ml}$ of the basal medium with one explant in each test tube. The explants were cultured at $25^{\circ} \mathrm{C}$ for six weeks under fluorescent light of $35-55 \mu \mathrm{mol} / \mathrm{m}^{2} / \mathrm{s}$ using $16 \mathrm{~h}$ illumination.

Number of leaves (leaf size at least two mm in length) and microtubers along with standard error were calculated after six weeks. 


\section{Results and Discussion}

Effects of different concentrations of growth regulators on leaf development in nodal cultures of different species of yam accessions are shown in Table 2 and Figs. 1-4. After six weeks of culture on MS, the nodal explants of Yam 23 and 25 failed to produce any leaf on IAA with $\mathrm{Kn}$, and on NAA with or without BAP. Seven accessions (Yam 15, 17, 18, 20, 21, 22, and 26) initiated 0.40 to 1.5 leaves per explant on T1. Other accessions totally failed to initiate leaves. Among the four
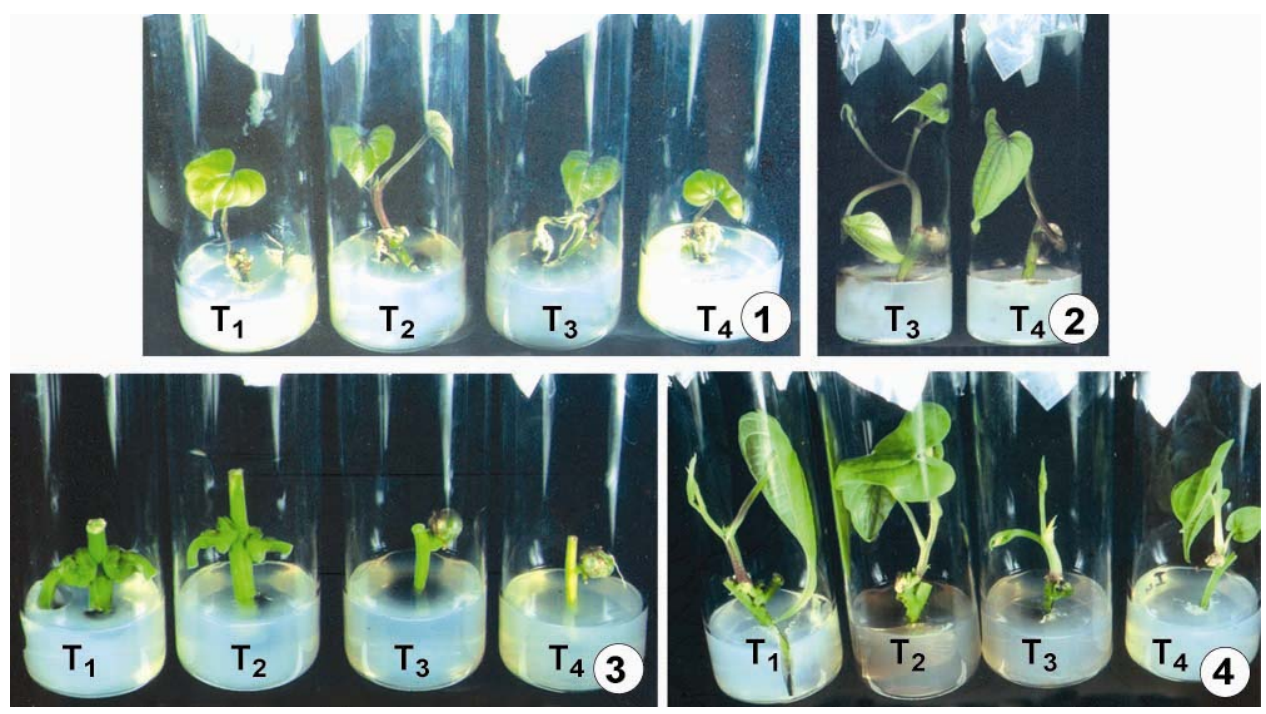

Figs. 1-4: Plantlets of yam developed from nodal explants on MS after six weeks of culturing. The four treatments are represented by T1, T2, T3 and T4, respectively. 1. Dioscorea polystachya (Yam 15). 2. D. bulbifera (Yam 21). 3. D. sansibarensis (Yam 17) and 4. D. japonica (Yam 22).

treatments, T2 appeared as the best one, whereas eight accessions (Yam 15, 17, $18,19,20,21,22$, and 26) initiated 0.33 to 2.17 leaves. On T3, Yam 15, 16, 18, 20, 21, 22, 24, and 26 initiated 0.40 to 2.80 leaves. The remaining accessions did not produce any leaf. On T4, Yam 15, 17, 18, 20, 21, 22, 24, and 26 initiated 0.29 to 1.0 leaves. Across the treatments, the highest mean number of leaves per explant was obtained in Yam 15 (1.76), followed by Yam 26 (1.16), 20 (0.99), 22 (0.98) and 18 (0.76). On the other hand, the highest mean number of leaves $(0.73)$ was obtained on T2, on the average, followed by T3 (0.71), T1 (0.64) and T4 (0.44). Considering accessions of the same species, Yam 15, 18, and 26 produced leaves in all the treatments and Yam 19 developed leaves on T2 only. It may be noted, that Yam 15 and 26 produced the highest (1.76) and the second highest (1.16) mean numbers of leaves among the accessions. When the number of leaves of four species of yam was compared, it was found that among the treatments, $D$. japonica produced 18,50 and $85 \%$ more leaves than D. polystachya, D. bulbifera and 
D. sansiberensis, respectively, after six weeks of cultivating the nodal explants (Table 2). Similarly, among the yam species, T2 appeared to be the best medium,

Table 1. Number of nodal explant used in different treatments of yam accessions.

\begin{tabular}{|c|c|c|c|c|c|}
\hline Species & $\begin{array}{l}\text { Accession } \\
\text { number }\end{array}$ & $\begin{array}{c}2 \mathrm{mg} / 1 \mathrm{IAA}+ \\
5 \mathrm{mg} / 1 \mathrm{Kn}+ \\
3 \% \text { sucrose-T1 }\end{array}$ & $\begin{array}{c}2 \mathrm{mg} / \mathrm{l} \mathrm{IAA}+ \\
10 \mathrm{mg} / 1 \\
\mathrm{Kn}+3 \% \\
\text { sucrose-T2 }\end{array}$ & $\begin{array}{c}0.2 \mathrm{mg} / 1 \mathrm{NAA} \\
+0.5 \mathrm{mg} / 1 \\
\text { BAP + 3\% } \\
\text { sucrose-T3 }\end{array}$ & $\begin{array}{c}0.5 \mathrm{mg} / 1 \\
\mathrm{NAA}+2 \% \\
\text { sucrose-T4 }\end{array}$ \\
\hline \multirow[t]{5}{*}{ D. polystachya } & Yam 15 & 5 & 6 & 5 & 6 \\
\hline & Yam 18 & 14 & 14 & 15 & 12 \\
\hline & Yam 19 & 9 & 9 & 9 & 8 \\
\hline & Yam 26 & 5 & 5 & 5 & 5 \\
\hline & Total & 33 & 34 & 34 & 31 \\
\hline \multirow[t]{4}{*}{ D. bulbifera } & Yam 16 & 6 & 7 & 6 & 5 \\
\hline & Yam 21 & 10 & 9 & 10 & 9 \\
\hline & Yam 24 & 5 & 5 & 5 & 5 \\
\hline & Total & 21 & 21 & 21 & 19 \\
\hline \multirow[t]{4}{*}{ D. sansibarensis } & Yam 17 & 5 & 5 & 5 & 5 \\
\hline & Yam 23 & 5 & 5 & 5 & 5 \\
\hline & Yam 25 & 5 & 5 & 5 & 5 \\
\hline & Total & 15 & 15 & 15 & 15 \\
\hline \multirow[t]{3}{*}{ D. japonica } & Yam 20 & 10 & 10 & 7 & 8 \\
\hline & Yam 22 & 12 & 12 & 9 & 7 \\
\hline & Total & 22 & 22 & 16 & 15 \\
\hline
\end{tabular}

Table 2. Effects of different growth regulators on leaf development in nodal culture of different species of yam accessions. ${ }^{a}$

\begin{tabular}{lcccccc}
\hline Species & $\begin{array}{c}\text { Acc. } \\
\text { number }\end{array}$ & $\mathrm{T} 1$ & $\mathrm{~T} 2$ & $\mathrm{~T} 3$ & $\mathrm{~T} 4$ & $\begin{array}{c}\text { Mean No. } \\
\text { of leaves/ } \\
\text { explant }\end{array}$ \\
& & & & & & \\
D. polystachya & Yam 15 & $1.25 \pm 0.48$ & $2.17 \pm 0.17$ & $2.80 \pm 0.37$ & $0.83 \pm 0.31$ & 1.76 \\
& Yam 18 & $0.93 \pm 0.25$ & $0.93 \pm 0.25$ & $0.67 \pm 0.25$ & $0.50 \pm 0.19$ & 0.76 \\
& Yam 19 & 0 & $0.44 \pm 0.44$ & 0 & 0 & 0.11 \\
& Yam 26 & $1.50 \pm 0.87$ & $1.67 \pm 0.88$ & $0.80 \pm 0.58$ & $0.67 \pm 0.33$ & 1.16 \\
D. bulbifera & Yam 16 & 0 & 0 & $1.00 \pm 1.0$ & 0 & 0.25 \\
& Yam 21 & $1.10 \pm 0.35$ & $0.33 \pm 0.24$ & $0.40 \pm 0.31$ & $0.78 \pm 0.40$ & 0.65 \\
& Yam 24 & 0 & 0 & $1.00 \pm 0.63$ & $0.75 \pm 0.25$ & 0.44 \\
D. sansibarensis & Yam 17 & $0.40 \pm 0.40$ & $0.50 \pm 0.29$ & 0 & $1.00 \pm 0.58$ & 0.48 \\
& Yam 23 & 0 & 0 & 0 & 0 & 0 \\
D. japonica & Yam 25 & 0 & 0 & 0 & 0 & 0 \\
& Yam 20 & $1.30 \pm 0.50$ & $1.60 \pm 0.40$ & $0.57 \pm 0.30$ & $0.50 \pm 0.27$ & 0.99 \\
\hline Mean & Yam 22 & $1.25 \pm 0.28$ & $1.17 \pm 0.47$ & $1.22 \pm 0.70$ & $0.29 \pm 0.18$ & 0.98 \\
\hline
\end{tabular}

aEach value represents a mean \pm standard error.

which produced 3, 13 and 39\% more leaves than T1, T3 and T4, respectively. The advantage of in vitro propagation lies in its ability to yield, in short time and 
limited space, a much larger number of true-to-type individuals than is possible by conventional methods. The nodes cultured on the propagating medium usually started to produce new shoots within three - four weeks. Differences of the in vitro responses among various species (D. polystachya, D. bulbifera, D. sansibarensis and D. japonica) have been observed (Figs. 1-4). Our objective was to find out the right combinations of growth regulators that provide the maximum number of leaves and microtubers. The amount of growth regulators was found to affect the production of leaves in different species. Comparing the performance between two concentration of $\mathrm{Kn}$ along with IAA and sucrose on leaf development, D. polystachya, D. sansibarensis and D. japonica responded better at a higher concentration of $\mathrm{Kn}(10 \mathrm{mg} / \mathrm{l})$, whereas D. bulbifera responded better in lower concentrations of $\mathrm{Kn}(5 \mathrm{mg} / \mathrm{l})$. On the other hand, comparing the performance between two concentration of NAA and sucrose, and the presence of BAP on leaf development, D. polystachya, D. bulbifera and D. japonica responded better in lower concentration of NAA $(0.2 \mathrm{mg} / \mathrm{l})$ fortified with a higher concentration of sucrose (3\%) and $0.5 \mathrm{mg} / 1$ BAP. On the other hand, $D$. sansibarensis responded better in a higher concentration of NAA $(0.5 \mathrm{mg} / \mathrm{l})$ with a lower concentration of sucrose $(2 \%)$ and without BAP. A good plant regeneration can be achieved by culturing petioles and internodal stem pieces of $D$. rotundata in the presence of 0.5 to $1.0 \mathrm{mg} / \mathrm{l}$ of NAA (Nwachukwu et al. 1996). D. abyssinica and D. margenotiana produced four - five new ones per each node on MS supplemented with $0.1 \mathrm{mg} / 1 \mathrm{NAA}$ and 1 or $2 \mathrm{mg} / 1 \mathrm{BAP}$ (Lauzer et al. 1992). The highest success came from the utilization of nodal segments containing axillary buds or buds with some adjacent stem and petiole tissues without leaves. The specific form of cytokinin or auxin may be important. Although Kn proved to be an effective cytokinin in nodal cultures of D. floribunda (Lakshmi et al. 1976). Mantell et al. (1980) found BAP to be preferable to Kn in apical shoot tips of $D$. alata. Both absolute and relative concentrations are also important. As auxin levels increase, there is a tendency for callus formation in D. bulbifera (Uduebo 1971). Low levels of auxin appear to be important in enhancing rooting. Cytokinin at moderate concentrations enhances shoot development; at higher levels, it promotes multiple shoots through precocious axillary shoot formation in D. bulbifera (Ammirato 1976). Chaturvedi (1975) reported that rooted singlenode cuttings of $D$. floribunda on a medium with $0.5 \mathrm{mg} / 1 \mathrm{NAA}$ and adenine sulphate, produce some tuberous tissues accompanied with the development of one or two shoots. Explants on a medium with $8.8 \mathrm{mg} / 1 \mathrm{BAP}$ produced on the average five - six shoot buds in 20 days. To regenerate whole plants from meristem tips, a proper balance of cytokinin and auxin is required. Different combinations of growth regulators were used for plantlet formation from meristem- and shoot tip cultures of D. alata (Mantell et al. 1980). 
Effects of different concentrations of growth regulators on microtuber development in nodal cultures of different yam species are shown in Table 3 and Figs. 1-4. After six weeks of cultivating the nodal explants on MS, no microtuber was found in Yam 16 (D. bulbifera) in any of the four treatments under study. The

Table 3. Effects of different growth regulators on leaf development in nodal cultures of different species of yam.

\begin{tabular}{lccccc}
\hline Species & $\mathrm{T} 1$ & $\mathrm{~T} 2$ & $\mathrm{~T} 3$ & $\mathrm{~T} 4$ & $\begin{array}{c}\text { Mean number of } \\
\text { leaves/explant }\end{array}$ \\
\hline D. polystachya & $0.77 \pm 0.18$ & $1.19 \pm 0.21$ & $0.82 \pm 0.21$ & $0.45 \pm 0.12$ & 0.81 \\
D. bulbifera & $0.58 \pm 0.22$ & $0.15 \pm 0.11$ & $0.71 \pm 0.34$ & $0.56 \pm 0.22$ & 0.50 \\
D. sansibarensis & $0.13 \pm 0.13$ & $0.15 \pm 0.10$ & $0.00 \pm 0.00$ & $0.31 \pm 0.21$ & 0.15 \\
D. japonica & $1.27 \pm 0.26$ & $1.36 \pm 0.31$ & $0.94 \pm 0.41$ & $0.40 \pm 0.16$ & 0.99 \\
\hline Mean & 0.69 & 0.71 & 0.62 & 0.43 & \\
\hline
\end{tabular}

Table 4. Effects of different growth regulators on microtuber development in nodal cultures of different species of yam accessions.

\begin{tabular}{lcccccc}
\hline Species & $\begin{array}{c}\text { Accession } \\
\text { number }\end{array}$ & $\mathrm{T} 1$ & $\mathrm{~T} 2$ & $\mathrm{~T} 3$ & $\mathrm{~T} 4$ & $\begin{array}{c}\text { Mean } \\
\text { number of } \\
\text { microtubers } \\
\text { /explant }\end{array}$ \\
\hline \multirow{5}{*}{ Dolystachya } & Yam 15 & 0 & $0.17 \pm 0.17$ & $0.20 \pm 0.20$ & $1.17 \pm 0.31$ & 0.38 \\
& Yam 18 & $0.57 \pm 0.20$ & $0.29 \pm 0.16$ & $0.40 \pm 0.19$ & $0.58 \pm 0.19$ & 0.46 \\
& Yam 19 & $0.11 \pm 0.11$ & $0.11 \pm 0.11$ & 0 & $0.13 \pm 0.13$ & 0.09 \\
D. bulbifera & Yam 26 & $0.75 \pm 0.25$ & $0.67 \pm 0.33$ & $0.40 \pm 0.24$ & $0.67 \pm 0.33$ & 0.62 \\
& Yam 16 & 0 & 0 & 0 & 0 & 0 \\
D. sansibarensis 21 & $0.40 \pm 0.16$ & $0.22 \pm 0.15$ & $0.10 \pm 0.10$ & $0.56 \pm 0.29$ & 0.32 \\
& Yam 24 & 0 & 0 & $0.20 \pm 0.20$ & $0.50 \pm 0.29$ & 0.18 \\
Yam 17 & $1.60 \pm 0.24$ & $1.25 \pm 0.25$ & $1.00 \pm 0.41$ & $0.75 \pm 0.48$ & 1.15 \\
& Yam 25 & $1.20 \pm 0.73$ & $0.60 \pm 0.24$ & $0.50 \pm 0.29$ & $0.50 \pm 0.29$ & 0.70 \\
Mean & Yam 20 & $0.80 \pm 0.32$ & $1.20 \pm 0.20$ & $0.25 \pm 0.25$ & $1.40 \pm 0.24$ & 0.96 \\
\hline & Yam 22 & $0.42 \pm 0.13$ & $0.70 \pm 0.21$ & $0.57 \pm 0.20$ & $0.38 \pm 0.18$ & 0.61 \\
& & $0.23 \pm 0.12$ & $0.22 \pm 0.15$ & $0.29 \pm 0.18$ & 0.29 \\
\hline
\end{tabular}

remaining accessions developed microtubers on $\mathrm{T} 4$, and their range was from 0.13 to 1.40 . On $\mathrm{T} 1$ almost all the accessions produced microtubers ranging from 0.11 to 1.60 except Yam 15, 16, and 24. On T2 and T3 almost all the accessions produced microtubers except Yam 24 on T2 and Yam 19 on T3. Across the yam accessions, the highest mean number of microtubers (0.58) was found on T4 followed by T1 (0.57), T2 (0.45) and T3 (0.32). Similarly, across the treatments, the highest number of microtubers was obtained in Yam 17 (1.15). Comparing the microtuber production of four species of Yam, D. sansibarensis produced 54, 60 
and $79 \%$ more tubers than D. japonica, D. polystachya and D. bulbifera, respectively, irrespective of the treatment. Among the yam species, T1 exhibited 8,26 and $46 \%$ more microtubers than T4, T2 and T3, respectively. Comparing the performance between two concentrations of $\mathrm{Kn}$ with IAA and sucrose on microtuber development, lower concentrations of Kn showed better performance

Table 5. Effects of different growth regulators on microtuber development in nodal cultures different species of yam.

\begin{tabular}{lccccc}
\hline Species & $\mathrm{T} 1$ & $\mathrm{~T} 2$ & $\mathrm{~T} 3$ & $\mathrm{~T} 4$ & $\begin{array}{c}\text { Mean number of } \\
\text { microtubers/explant }\end{array}$ \\
\hline D. polystachya & $0.39 \pm 0.11$ & $0.25 \pm 0.09$ & $0.26 \pm 0.10$ & $0.59 \pm 0.13$ & 0.37 \\
D. bulbifera & $0.21 \pm 0.10$ & $0.10 \pm 0.07$ & $0.10 \pm 0.07$ & $0.39 \pm 0.16$ & 0.20 \\
D. sansibarensis & $1.27 \pm 0.27$ & $1.00 \pm 0.15$ & $0.58 \pm 0.19$ & $0.92 \pm 0.21$ & 0.94 \\
D. japonica & $0.59 \pm 0.11$ & $0.43 \pm 0.12$ & $0.38 \pm 0.13$ & $0.33 \pm 0.13$ & 0.43 \\
\hline Mean & 0.61 & 0.45 & 0.33 & 0.56 & \\
\hline
\end{tabular}

in all the four species. This was the best among the four treatments. On the other hand, comparing the performance between two concentrations of NAA and sucrose, and the presence of BAP on microtuber development, D. polystachya, D. bulbifera and $D$. sansibarensis revealed better at higher concentrations of NAA along with lower concentration of sucrose and without BAP. However, D. japonica performed better at lower concentration of NAA along with a higher concentration of sucrose and the presence of BAP. Overall, BAP adversely affected the microtuber development. $D$. sansibarensis showed better performance in microtuber production than the remaining species. The number of microtubers per explant increased in course of the cultivation period in D. alata. The frequencies of tuberization were generally lower than those reported in earlier studies. The differences could be due to the fact that those authors made their final evaluations after 9-12 weeks of culture whereas in the present study the assessment was made much earlier (Jean and Cappadocia 1991 and Mantell and Hugo 1989). Uduebo (1971) first reported that nodal cuttings of D. bulbifera would form tubers on a medium supplemented with low levels of IAA. Nodal segments of both $D$. bulbifera and $D$. alata have produced tubers directly in culture (Ammirato 1982). In D. bulbifera, a single shoot, followed by a root, will form on MS without supplements. Shoot growth is repressed in the presence of NAA with the formation of a tuber. In contrast, zeatin promotes multiple shoot growth. In case of D. alata variety 'Farm Lisbon', tuber, shoot, and root growth were observed on MS and tuber formation and callusing in the NAAsupplemented medium. However, tuber formation without callusing occurred with the addition of $0.25 \mathrm{mg} / 1$ ABA. In studies with D. batatas (Asahira and Nitsch 1968), Kn promoted shoot growth in nodal segments, if the medium 
contained ammonium ions in addition to nitrate but in its absence tuber formation was induced. Many species of Dioscorea form small bulbils in their leaf axils; this often occurs during the rooting of nodal cuttings in the greenhouse (Coursey 1967). The formation of small tubers on plants grown from nodal and meristem cultures has been observed in D. floribunda (Chatuvedi 1975, Grewal et al. 1977). Ammirato (1982) reported that both D. alata var. 'Gemelos' and D. bulbifera var. sativa plants, after for four - five months of growth in continuous light, developed numerous aerial tubers. These tubers could be harvested or the cultures could be allowed to dry and the tubers together with the dry plants could be stored for up to six months. Microtuber formation was observed in other genera (Hu and Wang 1983), and the procedure became very important in the propagation of potato.

Comparing between leaf and microtuber development, D. japonica and D. polystachya exhibited an overall better performance in leaf production than the others, while $D$. sansibarensis was found better in microtuber development.

\section{Conclusion}

A higher concentration of Kn with IAA and sucrose proved to be the best for leaf development in D. japonica. A lower concentration of Kn with IAA and sucrose was the best for micro tuber development in D. sansibarensis. This technique can be used for micropropagation of yam species.

\section{Acknowledgements}

The authors would like to thank the German Foundation for International Development (DSE) and the Institute of Plant Genetics and Crop Plant Research (IPK, Gatersleben, Germany) for providing financial and technical supports to carry out the research work. They also thank Ms. Doris Büchner for her technical assistance in the experiment.

\section{References}

Ammirato PV (1976). Hormonal control of tuber formation in cultured axillary buds of Dioscorea bulbifera and D. alata. Plant Physiol. 57 (suppl): 66.

Ammirato PV (1982). Growth and morphogenesis in cultures of the monocot yam, Dioscorea. In: Plant Tissue Culture, Fugiwara A (Ed.), Maruzen,Tokyo, Japan, pp. 169170.

Ammirato PV (1984). Yams. In: Handbook of Plant Cell Culture, vol. 3, Ammirato PV, Evans DA, Sharp WR and Yamada Y (Eds.), MacMillan, New York, USA, pp. 327-354.

Asahira T and Nitsch JP (1968). Tuberisation in vitro: Ullucus tuberosus et Dioscorea. Bull. Soc. Bot. Fr. 115: 345-352. 
Asahira T and Yazawa S (1979). Bulbil formation of Dioscorea opposita cultured in vitro. Mem. Coll. Agric. Kyoto Univ. 113: 39-51.

Chaturvedi HC (1975). Propagation of Dioscorea floribunda from in vitro culture of singlenode stem segments. Curr. Sci. 44: 839-841.

Chaturvedi HC, Sharma AK, Sharma M, and Prasad RN (1982). Morphogenesis, micropropagation, and germplasm preservation of some economic plants by tissue cultures. In: Plant Tissue Culture, Fugiwara A (Ed.), Maruzen,Tokyo, Japan, pp. 687688.

Coursey DG (1967). Yams. Longman. Green and Co. London, p. 230.

Flora of North America (2006). Family list: Dioscoreaceae. 26: 479-484. Available from internet.http:/ / www.efloras.org/florataxon.aspx?flora_id=1\&taxon_id=110295 [Cited 5.2.2006].

Forsyth C and Van Staden J (1984). Tuberization of Dioscorea bulbifera stem nodes in culture. J. Plant Physiol. 115: 79-83.

Grewal S, Koul S, Sachdeva U and Atal CK (1977). Regeneration of Plants of Dioscorea deltoidea Wall. by apical meristem cultures. Indian J. Exp. Biol. 15: 201-302.

Hu CY and Wang PJ (1983). Meristem, shoot tip and bud cultures. In: Handbook of Plant Cell Culture, Vol. 1, Techniques for Propagation and Breeding, Evans DA, Sharp WR, Ammirato PV, and Yamada Y (Eds.), Macmillan, New York, USA, pp.177-227.

Islam MT, Dembele DP and Keller ERJ (2004). In vitro culture of yam seed (Dioscorea spp.). In: In Vitro Culture, Transformation and Molecular Markers for Crop Improvement, Islam AS (Ed.), Science Publishers, Inc. Enfield (NH) USA and Plymouth, UK, pp. 96-106.

Jean M and Cappadocia M (1991). In vitro tuberization in Dioscorea alata L. 'Brazo fuerte' and 'Florido' and D. abyssinica Hoch. Plant Cell Tissue Org. Cult. 26: 147-152.

Keller ERJ (2001). Dioscoreaceae. In: Mansfeld's Encyclopedia of Agricultural and Horticultural crops (except ornamentals), Hanelt P and Institute of Plant Genetics and Crop Plant Research (Eds.), Springer, Berlin, Vol. 4, pp. 2146-2174.

Lakshmi S, Bammi RK and Randhawa GS (1976). Clonal propagation of Dioscorea floribunda by tissue culture. J. Hortic. Sci. 51: 551-554.

Leunufna S. and Keller ERJ (2003). Investigating a new cryopreservation protocol for yams (Dioscorea spp.). Plant Cell Rep. 21: 1159-1166.

Lauzer D, Laublin G, Vincent G and Cappadocia M (1992). In vitro propagation and cytology of wild yams. Dioscorea abyssinica Hoch. and D. mangenotiana Miege. Plant Cell Tissue Organ. Cult. 28: 215-223.

Mantell SH, Haque SQ and Whitehall AP (1980). Apical meristem tip culture for eradication of flexous rod viruses in yams (Dioscorea alata). Tropical Pest Management 26: $170-179$.

Mantell SH and Hugo SA (1989). Effects of photoperiod, mineral medium strength, inorganic ammonium, sucrose and cytokinin on root, shoot and micro tuber development in shoot cultures of Dioscorea alata L. and D. bulbifera L. yams. Plant Cell, Tissue Org. Cult. 16: 23-37.

Ng SYC (1988). In vitro tuberization in white yam (Dioscorea rotundata Poir.). Plant Cell Tissue Org. Cult. 14: 121-128. 
Nwachukwu EC, Sonnino A and Mbanaso ENA (1996). Influence of NAA concentration and of explant source on plantlet regeneration in white guinea yam Dioscorea rotundata Poir. J. Genet. and Plant Breed. 50: 181-184.

Onwueme IC (1978). Tropical Tuber Crops, Yams, Cassava, Sweet potato and Cocoyams, John Willey and Sons, New York.

Uduebo AE (1971). Effect of external supply of growth substances on axillary proliferation and development in Dioscorea bulbifera. Ann. Bot. 35: 159-163. 